\title{
Expert evaluation of consumer properties of probiotics marketed in Ukraine
}

\author{
Iryna Chukhray ${ }^{1 \star}$, Halyna Bilushchak ${ }^{2}$, Lubov Kolyasa ${ }^{2}$, Olha Tokar $^{3}$, Andrij Datsko ${ }^{1}$ \\ ${ }^{1}$ Department of Organization and Economics of Pharmacy, Danylo Halytsky Lviv National Medical University, Pekarska 69, 79010 Lviv, \\ Ukraine \\ ${ }^{2}$ Department of Mathematics, Lviv Polytechnic National University, Bandera 12, 79013 Lviv, Ukraine \\ ${ }^{3}$ Department of International Information, Lviv Polytechnic National University, Bandera 12, 79013 Lviv, Ukraine
}

\section{ARTICLE INFO \\ Received 14 December 2017 \\ Accepted 01 March 2018}

\section{Keywords:}

probiotics,

expert evaluation.

\begin{abstract}
On the basis of results of experimental evaluation by 88 doctors and 100 pharmacists, the availability of information for them on probiotics has been investigated; new sources of such information have been detected, experts' attitude to new probiotics has been studied. In the course of administration or recommendation of probiotics, experts are, mainly, guided by standards of medical aid and by their own experience. The main favorable effects of probiotics on human organism, in respondents' opinion, are the normalization of the content of intestinal microflora and the normalization of functioning of digestive tract of human, as well as antialergetic and immunomodeling action. It is found that the main indication for application of probiotics are the syndrome of irritation of intestine and associated with antibiotic diarrhea. The averaged estimation (in points) of medicines has been calculated according to the following parameters: effectiveness, safety, frequency of prescription. With this, the competence of the experts was taken into account. The results of the carried out experts' estimation can be used for optimization of the system of choice of probiotics.
\end{abstract}

\section{INTRODUCTION}

One of the factors which determine the resistance of the human organism to the negative influence of environment is the character of the microflora of the human intestines. Still, deviation from the healthy composition of microflora in the human organism is a quite widespread phenomenon. This can lead to chronic diseases of the digestive tract, to allergies and to reduced immunity, etc.

The Nobel Prize laureate, Ilya Ilyich Mechnikov in 1907, was the first to pay attention to the important role of microbial flora in the development of human health. The scientist associated the phenomenon of longevity among the Balkan peasants with the consumption of a great amount of sour milk products, which he believed displaced pathogenic microorganisms and promoted the colonization of the intestines with sour-milk flora. He thus suggested to carry out sanitation of the human's intestinal microflora with help of special bacterial medicines or by means of sour-milk products containing live lactic acid bacteria [1].

\footnotetext{
* Corresponding author

e-mail: iryna_chukhray@ukr.net
}

The development of Mechnikov's idea concerning purposeful change in the content of microflora in the digestive tract through the enteral ingestion of cultures of lactic acid bacteria as antagonists to injurious bacteria has grown into a trend and has led to the creation of a new class of bacterial medicines - probiotics.

The word "probiotics" comes from the Latin "pro bio" which means "for life". The term "probiotic" was firstly used in 1965, by the scientists Daniel M. Lilly and Rosalie H. Stillwell as the opposition to the term "antibiotic". These scientists had in mind the substances which stimulated the growth and development of other microorganisms [2]. Further achievements enabled them to make amendments into the original definition of probiotics. In 1974, Robert B. Parker used the term "probiotics" for denoting bacterial medicines which possess the ability to regulate the bacterial microflora of the intestines. In accordance with his definition, probiotics are microorganisms or their components which are able to keep the balance of good intestinal microflora [3]. Later on, R. Fuller defined probiotics as any medicines consisting of living organisms which favourably influence the host organism at the expense of correcting intestinal 
microflora [4]. According to the definition suggested by the World Gastroenterology Organization (2017), probiotics are live microorganisms that confer a health benefit on the host when administered in adequate amounts [5]. Probiotics are naturally found in the body, and can be found in some foods, supplements and drugs.

The idea of using probiotic microorganisms therapeutically emerged about a hundred years ago. Yet, while the first probiotic medicines emerged in the middle of the $20^{\text {th }}$ century, it was not until the 1990's that intensive clinical investigation began.

Nowadays, the assortment of probiotic strains for restoration of microflora available on the market is quite wide, and it is presented by living cells of lactic acid bacteria or by inactivated probiotic flora, the products of metabolism or growth stimulators of physiological bacteria (prebiotics), as well as by synbiotics - combined medicines containing probiotics and prebiotics.

Probiotics are used mainly in gastroenterology for the treatment of different kinds of colitis, diarrhea, and other diseases [6,7]. New investigations have, however, revealed many other possibilities for the use of probiotics in gynecology, in the treatment of dermatological diseases, and others $[8,9]$.

Most frequently, Bifidobacterium and Lactobacillus are employed as probiotic medicines. Beyond the aforementioned microorganisms, probiotics can contain the bacteria of other strains and kinds whose effectiveness is not always clinically proven. However, some probiotics strains such as Lactobacillus reuteri DSM 17938; Lactobacillus acidophilus, Lactobacillus lactis, Pediococcus acidilactici; Lactobacillus casei subsp. rhamnosus GG; Bifidobacterium longum BB536; Bifidobacterium lactis BB12 and Streptococcus thermophilus TH4; Carnobacterium maltaromaticum CB1; S. cerevisiae ML01 and Saccharomyces cerevisiae ECMo01 have been generally recognized as safe probiotics by the Food and Drug Administration in the United States [10]. The aim of this work was the improvement in providing probiotics for people by means of enhancement of the system of their choice.

\section{MATERIAL AND METHODS}

The methodology was based on a systematic approach and analysis. The main methods were statistical data: analysis of variance and correlation-regression analysis, as well as expert estimates. The Kendall Concordance Coefficient is used to assess the extent to which expert opinions are consistent.

The subject of our investigation was information from questionnaires of expert evaluation of probiotics by doctors and pharmacists. The questionnaire which was used in the investigation consists of the three parts: introduction (data from passport), information and expert conclusions.

In the introductory part, there were questions concerning the place of work and the occupation of the respondent, his/her experience of work, qualification category and academic degree. This section enabled us to estimate the experts' competence.
The second part of the questionnaire - information contained questions of the type of alternatives to be chosen and of questions in which respondents could express their own opinions. The informational block contained questions which concerned the sources of information about probiotics and their availability, respondents' attitude to new probiotics, to factors of influence on the choice of probiotics, their favourable effects upon the organism and indication to application, safety of use of probiotics (possibility of side effects). The experts had also the possibility to express their attitude to the effectiveness of consumption probiotic products which are not for sale in pharmacies (kefirs, yogurts, etc.) with preventive and therapeutic purpose.

In order to detect priorities in the choice of probiotics by doctors and pharmacists, we have developed two types of the part of a questionnaire which contain the expert conclusion. Doctors were asked to estimate the effectiveness and safety of probiotics, to indicate the frequency of their administration, and to carry out VEN-analysis (vital, essential and non essential categories). In the third block (expert conclusion) of the questionnaire, pharmacists estimated the demand for probiotics.

We also listed 24 kinds of medicines containing probiotics and 24 special food products containing probiotics into the part of the questionnaire which contained expert conclusions.

For estimation of probiotics, a three-grade scale was developed, according to which a highly effective medicine which is safe and also is the most frequently administered received one point for each of the parameters (in total, three points). The medicine of middle effectiveness which induced inconsiderable side effects and is not frequently administered was assigned two points. One point was assigned to the probiotic which, in the experts' opinion, is of low effectiveness or which causes considerable side effects and is rarely administrated.

Estimation of the results was conducted with taking into account the experts' level of competence. When determining the competence level (in points) of a doctor, his/her work experience (less than 5 years, 5-10, 11-20 and above 20 years); presence of qualification category (no category, first, second, or higher category), presence of academic degree (for doctors) were taking into account. And when determining the competence level of an expert pharmacists, we took into account his/her speciality level (secondary or higher education). According to the number of points awarded, the experts were grouped into high (7-9 points), middle (4-6 points) and low (1-3 points) for physicians, while for pharmacists, the point totals were 2-3 points. According to the number of points awarded, the experts were divided into groups of high, middle and low competence level [11].

\section{RESULTS AND DISCUSSION}

The participants were 88 doctors and 100 pharmacists.

As a result of the carried out estimation of the respondents' competence as to their professional and qualification characteristics, we found that $64 \%$ of all doctors and $20 \%$ of all pharmacists were of high level of competence, $16 \%$ 
and $62 \%$ were of middle level, and $20 \%$ and $18 \%$ of all respondents were of low level.

What is more, we established that the doctors' answers to all the questions of informational parts of their questionnaires are of high agreement (Kendall's coefficient was $0.74674, \mathrm{p}<0.00000)$. The analysis of pharmacists' questionnaires also has indicated high agreement (Kendall's coefficient was $0.76218, p<0.00000$ ) according to the answers to the questions concerning the availability of information about probiotics, attitude to new probiotics and their favorable effects on the human organism.

In addition, the overwhelming majority of experts $(90 \%$ of all doctors and $78 \%$ of all pharmacists) consider information about probiotics to be freely available and that they administer new probiotics after analysis of results of their clinical use (80\% and 59\%, respectively).

According to the survey conducted, the main sources of information for doctors about probiotics are scientificpractical conferences $(89 \%)$ and medical representatives of pharmaceutical companies-producers $(86 \%)$. It should be noticed that $68 \%$ of all pharmacists receive the information about probiotics from medical representatives as well. More than half of all doctors (59\%) and a third of all pharmacists $(30 \%)$ also receive their information from advertising prospects. The Internet is, moreover, a source of information about probiotics for $54 \%$ of all doctors and $66 \%$ of all pharmacists. Professional editions are used by one-third of the participating doctors $(29 \%)$ and a one-fifth of all pharmacists $(22 \%)$. An inconsiderable part of experts use reference-books on probiotics and specialized insets (11\% and $8 \%$ ) as sources of information (11\% and $10 \%)$.

Thus, company-producers play a considerable role in informing the medical and pharmaceutical specialists about probiotics.

When administrating probiotics, doctors are guided mainly by standards of medical aid $(80 \%)$ and by their own practical experience $(77 \%)$. For pharmacists, in recommending a probiotic, a more important factor is their own experience (70\%), and a less important factor is standards of medical aid (44\%). Data from literature are used by approximately one-third of all respondents (32\% of all doctors and $28 \%$ of all pharmacists), a less important factor for doctors (11\%) and pharmacists (18\%) is advice from their colleagues concerning administration and recommendation of probiotics.

The main favorable factors of probiotics on the human organism, in the doctors' opinion, are the normalization of the content of intestinal microflora and of the function of the human digestive tract, as well as antialergetic and imunomodulating action. Pharmacists recognize the same favorable effects of probiotics as doctors, although they do not assign antialergetic action to probiotics.

Doctors prescribe probiotics mainly against irritable bowel syndrome $(66 \%)$ and for prevention and treatment of post-antibiotic diarrhea (47\%). One-fourth of the respondents $(24 \%)$ consider the taking of probiotics for the prevention of travellers' diarrhea to be effective, one-fifth (20\%) - for prevention of respiratory diseases, $19 \%$ - for eradication of Helicobacter pylori, and 16\% - for ulcerative colitis.
Among the other spheres of application of probiotics, the doctors consider the aforesaid allergic diseases and intestinal infections. Pharmacists have some otherwise opinions concerning the aforesaid question. The main indications for use of probiotics that pharmacists consider are post-antibiotic diarrhea $82 \%$ ) and irritable bowel syndrome (56\%). Almost half of the respondents (48\%) find it expedient to take probiotics to prevent travellers' diarrhea.

Only $5 \%$ of the doctors and $2 \%$ of the respondents with pharmaceutical education indicated that they observed adverse side effects during the taking of probiotics (e.g. constipation), and this fact confirmed the high level of safety of probiotical medicines.

The overwhelming majority of doctors $(68 \%)$ and pharmacists $(66 \%)$ consider the taking of foods with probiotics (kefirs, yogurt) with preventive purpose to be effective, though, as to purpose of treatment, their taking is considered to be effective only by small part of the respondents $-14 \%$ of all doctors and $8 \%$ of all pharmacists.

The analysis of the experts' part of the questionnaire which concerns estimation, showed that the doctors had provided estimation opinion for all the 48 probiotics which were to be estimated by them. On average, each doctor provided an estimation opinion on 14 probiotics (from 4 to 40 medicines), i.e. about one-third of all medicines listed.

We saw high agreement among the doctors' opinions (Kendall's coefficient $0.62632, \mathrm{p}<0.00000$ ) concerning the probiotic products of Bifidumbakteryn-Biofarma, Bifidumbakteryn, Bifiform, Yohurt, Yohurt Rozel, Lakto G, Lineks Bebi, Lineks forte, Mutaflor and Spazmolak.

The expert's evaluation of individual probiotics was carried out by 1 to 56 of all doctors; opinions were provided by more than $30 \%$ of all experts on 14 kinds of medicines which contain probiotics and 8 special kinds of food containing probiotics.

In calculating the averaged evaluation with respect to points, we have taken into consideration the opinion of experts whose competence is middle and high. In so-doing, according to the doctors' opinion, an averaged point-evaluation which is higher than the middle-level $\left(\bar{O}_{\mathrm{s}}=1.7\right)$ was given to 12 probiotics ( 6 medicines and 6 special kinds of foods).

Pharmacists have also provided estimation opinion on all the probiotics which were to be considered. On average, each expert provided an estimation opinion on 36 probiotics - from 29 to 48 . Estimation opinions on each individual probiotic were also provided by $48 \%-100 \%$ of all experts. It should be noticed that an opinion was rendered on the medicine Lineks by all the respondents.

A higher than the middle-level point averaged evaluation $\left(\bar{O}_{\mathrm{s}}=2\right)$, in the opinion of pharmacists, was given to 23 probiotics, practically half of these $(48 \%)$ are medicines, the others - special foods $(52 \%)$. Thus, it can be asserted that the form of the registration of a probiotic is not a decisive factor for recommendation of it by pharmacists.

Higher demand, in the opinion of pharmacists, is observed for probiotics which are registered as medicines, though the special food product Biohaya (Sweden) also received high evaluation. This item has been registered in 70 countries throughout the world, and its effectiveness has 
Table 1. Results of the experts evaluation of probiotics

\begin{tabular}{|c|c|c|c|c|c|c|}
\hline \multirow{2}{*}{$\begin{array}{c}\text { Probiotic } \\
\text { (dosage form) }\end{array}$} & \multicolumn{2}{|c|}{ Averaged evaluation } & \multicolumn{2}{|c|}{ Rating } & \multicolumn{2}{|c|}{ Number of mentions \% } \\
\hline & Doctors & Pharmacists & Doctors & Pharmacists & Doctors & Pharmacists \\
\hline Biohaya ORS (powder) & 1.33 & 1.74 & 1 & 12 & 49 & 83 \\
\hline Biohaya (drops) & 1.41 & 1.38 & 2 & 4 & 76 & 98 \\
\hline Bulardi (sachet) & 1.42 & 2 & 3 & 23 & 38 & 63 \\
\hline Biohaya (pills) & 1.47 & 1.63 & 4 & 9 & 38 & 93 \\
\hline Lineks bebi (powder) & 1.48 & 1.53 & 5 & 7 & 43 & 93 \\
\hline Enterozhermina (suspension) & 1.5 & 1.37 & 6 & 2 & 76 & 100 \\
\hline Prema (sachet) & 1.57 & 1.9 & 7 & 20 & 38 & 76 \\
\hline Prema Dlia ditei (drops) & 1.61 & 1.41 & 8 & 5 & 68 & 100 \\
\hline Lineks (capsules) & 1.6 & 1.8 & 9 & 14 & 32 & 73 \\
\hline Enterol (powder) & 1.62 & 1.3 & 10 & 1 & 49 & 93 \\
\hline Enterol (capsules) & 1.65 & 1.38 & 11 & 3 & 62 & 98 \\
\hline Bifiform (capsules) & 1.66 & & 12 & & 54 & \\
\hline Lineks forte (capsules) & & 1.49 & & 6 & & 95 \\
\hline Laktovit forte (capsules) & & 1.55 & & 8 & & 98 \\
\hline Yohurt (capsules) & & 1.71 & & 10 & & 93 \\
\hline Bifidumbakteryn - Biofarma (powder) & & 1.73 & & 11 & & 93 \\
\hline Laktomun (sachet) & & 1.8 & & 13 & & 88 \\
\hline Rotabiotyk (capsules) & & 1.82 & & 15 & & 83 \\
\hline Rotabiotyk beibi (powder) & & 1.82 & & 16 & & 85 \\
\hline Bioghaya Protektis z D3 (drops) & & 1.87 & & 17 & & 73 \\
\hline Prema dlia ditei duo (drops) & & 1.89 & & 18 & & 68 \\
\hline Latsium (powder) & & 1.9 & & 19 & & 81 \\
\hline Bulardi (capsules) & & 1.92 & & 21 & & 63 \\
\hline Subalin (powder) & & 1.94 & & 22 & & 88 \\
\hline
\end{tabular}

been confirmed by clinical trials [12]. Biohaya is also recommended by the Ukrainian Association of Neonatologists [13].

The results of experts' evaluation of probiotics by doctors and pharmacists are given in Table 1.

According to the data of the carried-out expert evaluation, it can be asserted that high evaluations from doctors were given to probiotics which are of high demand in pharmacies, with the exception of Bifiform. However, some of the probiotics which are in demand in pharmacies, in the doctors' estimation, had average-point evaluation by far lower than the average value. For example, Lineks forte $-\mathrm{Os}=1,7$, Laktovit forte (in capsules) - Os $=1,71$, BifidumbakterynBiofarma $-\mathrm{Os}=1,73$. The other probiotics which are found by pharmacists as those of high demand are not often prescribed by doctors. Thus, in the formation of demand for these probiotics, other factors play important roles. Among these are advertising and information obtained from the producing firms (from medical representatives).

\section{CONCLUSIONS}

On the basis of the data which we obtained in the course of the carried out questionnaire interrogation, a high level of recommendation for probiotics can be established. Herein, the source of information about probiotics are sufficiently accessible, but the influence of information from the producing companies and from Internet-source is also significant. In our study, estimations of effectiveness, security, VENtest, frequency of recommendation and demand, as well as mean valued estimations (in points) of probiotics have been calculated. In so-doing, a group of probiotics of the highest rating has been established, albeit some divergences between the opinions from physicians and those from experts in pharmacology have been detected. The experts' estimations of probiotics which was carried out will contribute to the appropriate application of these medicaments and to the establishing of optimal variety within the pharmacies and chemists, hence, the quality of pharmacotherapy will be improved. The results of the carried out investigation can, therefore, be used for optimization of the choice of probiotics.

\section{REFERENCES}

1. Mechnykov II. Etiudy optymizmu. Moskva: Nauka, 1988: 164-165. Available at: http://www.klex.ru/5by.

2. Lilly DM, Stillwell RH. Probiotics: growth-promoting factors produced by microorganisms. Science. 1965;147(3659):747-8.

3. Fuller R. Probiotics in man and animals. J Appl Bacteriol. 1989;66(5):365-78.

4. Parker RB. Probiotics, the other half of the antibiotic story. Anim. Nutr. Health. 1974;29:4-8. 
5. Guarner F, Sanders M-E, Eliakim R, Fedorak R, Gangl A, Garisch J et al. WGO Global Guideline. Probiotics and prebiotics. Available at: http://www.worldgastroenterology.org/guidelines/global-guidelines/ probiotics-and-prebiotics/probiotics-and-prebiotics-english.

6. Goldenberg JZ, Lytvyn L, Steurich J, Parkin P, Mahant S, Johnston BC. Probiotics for the prevention of pediatric antibiotic-associated diarrhea. Cochrane Database of Syst. Rev. 2015:12. Available at: http://www.cochrane.org/CD004827/ IBD_probiotics-prevention-antibiotic-associated-diarrhea-children.

7. Naidoo K, Gordon M, Fagbemi AO, Thomas AG, Akobeng AK. Probiotics for maintenance of remission in ulcerative colitis. Cochrane Database of Syst. Rev. 2011:12. Available at: http://www. cochrane.org/CD007443/IBD_probiotics-for-maintenanceof-remission-in-ulcerative-colitis.

8. Senok AC, Verstraelen H, Temmerman M, Botta GA .Probiotics for the treatment of bacterial vaginosis. Cochrane Database of Syst. Rev. 2009:4. Available at: http://www.cochrane.org/CD006289/ STI_probiotics-for-the-treatment-of-bacterial-vaginosis.
9. Boyle RJ, Bath-Hextall FJ, Leonardi-Bee J, Murrell DF, Tang MLK. Probiotics for treating eczema. Cochrane Database of Syst. Rev.2008;4. Available at: http://www.cochrane.org/CD006135/ SKIN_probiotics-for-treating-eczema.

10. Chalas R, Janczarek M, Bachanek T, Mazur E, Cieszko-Buk M, Szymanska J. Characteristics of oral probiotics - a review. Curr. Issues Pharm. Med. Sci. 2015;29: 8-10.

11. The technique of complex estimation of medicines basing on the example non-steroidal anti-inflammatory medicines for treatment of rheumatoid arthritis/ Methodical recomendational/ N.L.Herbolka, O.L.Hrom, Danylo Halytsky Lviv National Medical University. Kyiv, 2008. $-21 \mathrm{p}$

12. Gutiérrez-Castrellón P, Indrio F, Bolio-Galvis A, Jiménez-Gutiérrez C, Jimenez-Escobar I, López-Velázquez G. Efficacy of Lactobacillus reuteri DSM 17938 for infantile colic: Systematic review with network meta-analysis. Medicine (Baltimore). 2017 Dec;96(51):e9375. doi: 10.1097/MD.0000000000009375. - Available at: https://www.ncbi. nlm.nih.gov/pubmed/29390535.

13. Association of neonatologists of Ukraine. - Available at: http://old. neonatology.org.ua/uk/. 